\title{
Guest Editorial : Dr Hrutvij Bhatt
}

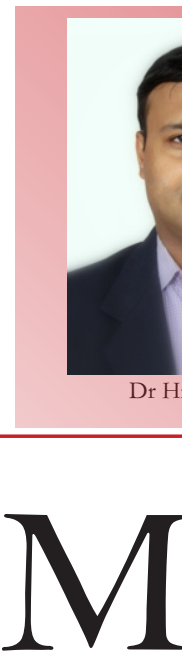

\author{
Dr Hrutvij Bhatt \\ Consultant spine surgeon \\ The Spine Clinic, Shalby Hospital \\ Ahmedabad, Gujrat, India. \\ Email: hrutvij.bhatt@gmail.com
}

medical students and often wonder why it's a compulsory part of our curriculum.

Basically thesis writing is the first step and an important exercise to train us about research. Every year more than six to seven thousand medical thesis are been written in our Country, However very few (less than 10\%) see the light of publication. A lot of them do not get published in mainstream journals, as authors feel it is not good enough or there are lacunae or there are issues with the designing of the study. However all thesis do involve collection of data which has potential to answer a question. If we consider these numbers then we can imagine how much important data do not get the light of publication.

Even if the thesis has a small learning point or a small practical or statistical point to make, we feel it is worth publishing. Journal of Medical thesis is an attempt to fill up these lacunae and provide a platform for publication of the more and more medical thesis in form of publications.

Journal of Medical thesis is unique Journal dedicated to publishing medical thesis all across the globe. It is an initiative of International Organisation of Research Groups through the Indian Or thopaedic Research group.

JMT will not only provide an opportunity to students to publish the medical thesis and get credit to themselves and their teachers, but will also help to reduce the plagiarism. In addition to being a Journal, JMT is also envisioned to be a platform where thesis can be discussed and help regarding Thesis can be provided. Through JMT we will be trying to improve the standard of thesis and research in our country.

JMT will also like to thank the Editorial board members who believed in our idea and supported us when we were putting our first steps.

And as I conclude with each and every drop of water makes a mighty ocean likewise each thesis work getting published can add to important data which can be very helpful for various meta analysis and systemic reviews. 